Running head: VICTIMS OF VIOLENT FORENSIC PATIENTS

\title{
Who are the Victims of NGRI Acquittees? A Study of Belgian Internees
}

Inge Jeandarme ${ }^{1}$, Laura Vandenbosch ${ }^{2}$, Marc Groenhuijsen ${ }^{3}$, T. I. Oei ${ }^{3}$ \& Stefan Bogaerts ${ }^{4}$

${ }^{1}$ Knowledge Centre Forensic Psychiatric Care (KeFor) OPZC Rekem, Rekem, Belgium,

${ }^{2}$ Leuven School for Mass Communication Research, KU Leuven

${ }^{3}$ Tilburg University, Tilburg, the Netherlands

${ }^{4}$ Tilburg University, Tilburg, the Netherlands; KARID, FIVOOR, Forensic Psychiatric Centre The Kijvelanden, Rotterdam, the Netherland

Author Note

Inge Jeandarme obtained a MD in psychiatry and criminology and is currently $\mathrm{PhD}$ student at the Tilburg Law school in the Netherlands. Her research topics are: forensic psychiatry, risk assessment and recidivism. Laura Vandenbosch, is an assistant professor at the Leuven School for Mass Communication Research, KU Leuven. Her main research interests include media psychology and the well-being of adolescents. Marc Groenhuijsen is professor in criminal law, 
criminal procedure, and victimology at Tilburg University. He is a part-time judge in the Court of Appeals in Arnhem/Leeuwarden and member of the Royal Netherlands Academy of Arts and Sciences. T.I. Oei is emeritus endowed professor of Forensic Psychiatry at Tilburg Law School in the Netherlands. He has (co-)authored more than 500 publications on psychopathology, social psychiatry, clinical psychiatry, psychotherapy, and forensic psychiatry (books, papers, abstracts, book chapters, oral presentations). He has given for the last 30 years supervision in group \& family therapy, and in psychoanalytical psychotherapy and psychoanalysis. He is a member (of the Scientific Committee) of the International Academy of Law and Mental. Health. Stefan Bogaerts, is a psychologist Msc, criminologist, Msc, $\mathrm{PhD}$, psychotherapist GPP and full professor at Tilburg University, Department of Developmental Psychology. He is vice-chair of the department, Academic Director of the master Clinical Psychology and Mental Health, and Head Science and Treatment Innovation of Fivoor (Kijvelanden, Aventurijn, Palier \& FPC Gent). His main research topics are: forensic psychopathology, self-regulation, risk assessment and forensic treatment.

Corresponding concerning this article should be addressed to Inge Jeandarme, KeFor, Daalbroekstraat 106, 3621 Rekem, Belgium. E-mail: inge.jeandarme@opzcrekem.be 


\section{Acknowledgments}

This project was funded by Limburg Sterk Merk (LSM) and the Public Psychiatric Care Centre Rekem (OPZC Rekem). We wish to thank the clinicians and clients of the medium security units and the CPS Chairmen for their cooperation and Claudia Pouls for help with the data collection. 


\begin{abstract}
Background. The limited literature on victim characteristics of offenders found not guilty by reason of insanity (NGRI) shows that most victims are adults who are known to the offender. It is currently unclear whether victims are mainly male or female or whether there are differences in the type of victims according to the offenders' psychiatric disorder.

Method. Victim characteristics were retrospectively collected from 362 NGRI acquittees, and the influence of psychiatric diagnoses on victim profiles was examined.

Results. Victims were mainly adult acquaintances and were equally likely to be male or female. Family members and caregivers were the most frequent type of acquaintance victims. Further analyses suggest that these victim characteristics are similar for perpetrators with different psychiatric diagnoses.

Conclusion. Victimization of strangers and minors was unlikely in NGRI offenders.

Keywords: victims, forensic psychiatry, not guilty by reason of insanity
\end{abstract}




\section{Who are the Victims of NGRI Acquittees? A Study of Belgian Internees}

Studying victim characteristics in mentally disordered offenders (MDOs) enables effective treatment and the prevention of future victims (Mezey, 2007). In contrast to the scholarly attention to MDOs (e.g., Bowers et al., 2011; Coid, Kahtan, Gault, Cook, \& Jarman, 2001) however studies have rarely examined their victims. Moreover, studies addressing the characteristics of victims of MDOs found not guilty by reason of insanity (NGRI) after being accused of a crime are even more scarce. This is surprising because NGRI acquittees tend to have more victims compared to individuals who raise the insanity defense and are found guilty (e.g. 1.5 vs. 0.7 in Gulayets, 2016). In addition, violence committed by people with severe mental disorders cannot simply be explained by their psychiatric symptoms. Violence derives from heterogenic factors, including internal and external factors. The internal model suggests that individual factors such as antisocial personality characteristics or impulsivity contribute to violent behavior. The external model emphasizes the role of environmental factors (e.g., social circumstances) and situational or interactional factors focusing on the relationship between victim and perpetrator.

\section{Victim's Gender and Age}

The mean age of victims in NGRI offender populations has rarely been reported. One study found that the vast majority (95.7\%) of NGRI acquittee cases involved adult victims (Gulayets, 2016). Menezes , Oyebode, and Haque (2009) found a similar trend in Zimbabwe, although they did report a larger minority of minor victims (i.e., 24\% of the victims were 16 years and younger). These findings are in line with studies focusing on more broadly defined MDO populations, which found prevalence rates of offenders with minor victims to be below $20 \%$ on average (e.g., Gradillas, Williams, Walsch, \& Fahy, 2007; Nordstrom \& Kullgren, 
2003b). However, in NGRI sex offenders, $50 \%$ of the victims were minor victims (Novak, McDermott, Scott, \& Guillory, 2007).

Research examining the gender of victims of NGRI offenders has shown mixed results. Crocker et al. (2015) examined victim gender in a Canadian ${ }^{1}$ sample and found that victims were males in slightly more than half of the index offences involving crimes against a person (53.3\%), whereas Gulayets (2016) found the opposite (55.2\% female victims). Menezes et al. (2009) also found that the total number of female victims (55.4\%) was greater than the total number of male victims (44.6\%). According to Cirincione, Steadman, and McGreevy (1995), insanity acquittals were more likely in cases of male victims than female victims.

\section{Offender-Victim Relationship}

Most research has focused on the relationship between victims and offenders who were found NGRIs. In terms of the victims' relationship with the accused, $26.7 \%$ of the total number of victims were strangers, $21.1 \%$ were acquaintances, $16.4 \%$ were family members, and $13.1 \%$ were professionals (e.g., police officers and mental health staff) (Livingston, Wilson, Tien, \& Bond, 2003). In contrast, Crocker et al. (2015) reported that family members (including partners) $(33.7 \%)$ in a Canadian sample were the most targeted victims of index offences against a person, followed by professionals (22.9\%), strangers $(22.7 \%)$, and other people known to the accused (20.7\%). Similar findings were presented in an American study, that found that family victims $(30.8 \%)$ were the most frequent acquaintance victims (G. Parker, 2004). Crocker, Seto, Nicholls, and Côté (2013) focused on very serious offences only (including homicide, attempted manslaughter and sexual offences), and found differences in the distribution of accused people's relationships with the victims according to the type of index offence. Particularly in cases of murder or attempted murder, the victims were most often family members (57\%), with parents 
being the most likely victims followed by partners or spouses. Victims of sexual offenders were more likely to be strangers (43\%) and less likely to be family members (16.7\%). Studies comparing NGRI acquittees to offenders found criminally responsible confirmed that the chance of NGRI acquittal was associated with acquaintance victims (Cirincione et al., 1995; I. Parker, 1987). However, one study with a small sample size ( $n=36$ NGRI offenders) studying only primary victims found a larger number of stranger victims (42.9\%) and failed to find a significant difference between both groups (Gulayets, 2016).

Taken together, it seems that studies on NGRI populations generally agree that there are more acquaintance victims than stranger victims, which corresponds to research on more broadly defined MDO populations (e.g., Gow, Choo, Darjee, Gould, \& Steele, 2010; Gradillas et al., 2007). As noted by Swanson et al. (1998), social contact is a mixed blessing for people with a severe mental illness. Particularly for those with severe mental illness such as psychotic or bipolar disorders, frequent contact with others may produce conflict, stress, and opportunities for physical violence (Kamperman et al., 2014). Individuals in a close relationship with the psychiatric patient are more likely to be assaulted (Pinna et al., 2016). As such, several studies have reported a substantial proportion of relatives (i.e., family members and intimate partners) among the victims of NGRI offenders (Crocker et al., 2015; Crocker et al., 2013; Menezes et al., 2009; I. Parker, 1987). Moreover, researchers who identified a so-called key cluster of risk factors of becoming a victim have given a central focus on relatives. This cluster includes being a mother or immediate co-habiting relative of an individual who is financially dependent and diagnosed with schizophrenia or impaired by substance abuse and a low user or non-user of mental health services (Estroff, Swanson, Lachicotte, Swartz, \& Bolduc, 1998). Even in cases of repeated violence before and after hospitalization, the target was the same person in the majority 
of the cases, most often a spouse, an intimate relative, or other family member (Tardiff, Marzuk, Leon, \& Portera, 1997).

For obvious reasons, different victim profiles can be expected during hospitalization since inpatients have fewer opportunities to assault relatives while being institutionalized. Few data are available concerning hospitalization status of NGRI offenders, but results seem to suggest that at least in some cases, the victims involved are mental health professionals or copatients (e.g., Crocker et al., 2015). Most inpatient studies on more broadly defined MDOs found that hospital staff in particular were victimized, as were other patients but to a lesser extent (e.g., Gow et al., 2010; Weizmann-henelius \& Suutala, 2000). In addition, hospital staff, nurses, and ward staff members (i.e., individuals who have the closest contact with the patient) were more frequently victimized than clinical or supervisory staff (e.g., Kelly, Subica, Fulginiti, Brekke, \& Novaco, 2015; Nicholls, Brink, Greaves, Lussier, \& Verdun-Jones, 2009).

However, not all studies show consistent results regarding which type of acquaintance victims (hospital staff or other patients) are the most likely to become victims of inpatient MDOs. For example, some studies found that it was equally likely (Nicholls et al., 2009) or even more likely (Bader, Evans, \& Welsh, 2014; Daffern, Mayer, \& Martin, 2003) that victims were co-patients than staff. Several possible explanations for these different findings can be given. First, violent incidents toward staff are more likely to be formally reported than those directed to other patients. Second, there may be a gender-difference. Results in Nicholls et al. (2009) suggest that men rather tend to be seriously violent towards fellow patients than against staff, whereas women are more likely to perpetrate serious violence against staff instead of fellow patients. Third, the practice of secluding potentially violent patients may increase the likelihood of aggression against staff but reduce the likelihood of aggression towards patients. 


\section{Type of Psychiatric Disorder}

To the best of our knowledge, studies investigating the victim-offender relationship in NGRI offenders did not focus on the psychiatric disorder of the offender. In MDOs, Johnston and Taylor (2003) found that regardless of the type of personality disorder, having a classified personality disorder was positively associated with stranger victimization. This finding was not confirmed in another study (Goethals, Gaertner, Buitelaar, \& van Marle, 2008). Goethals et al. (2008) investigated whether victims of psychotic patients (with or without a combined personality disorder) detained under the Dutch Entrustment Act would be more likely to be a relative, friend, or acquaintance than the victims of patients with only a personality disorder, but they found no significant difference. As Goethals et al. (2008) argued psychotic forensic patients with or without personality disorder are considered as one group in most studies (including their own due to methodological issues), but it may be important to study them as separate groups because this co-morbid group may be more similar to personality disordered patients. Psychotic patients with a comorbid personality disorder may be an interesting group to study since previous research showed that this group may be more at risk to commit violence (e.g., Witt, van Dorn, \& Fazel). So far, no study has explored whether the type of psychiatric disorder relates to differences in the gender or age of victims. While the risk of violent behavior is greater in individuals with a severe mental illness, it should be emphasized that most psychiatric patients do no victimize other persons. In line with these findings, scholars generally agree that patients with a severe mental illness run a higher risk of victimization than the regular population (Kamperman et al., 2014; Maniglio, 2009). In addition, in-patients are regarded as having higher risk of victimization than outpatients (de Mooij et al., 2015). 
In sum, victims of NGRI offenders are in many ways similar to victims of MDO offenders; i.e., they are likely to be adult victims who are known to the offender and they are equally likely to be male or female. However, the available research is still limited in its scope and has rarely included in-depth analyses.

\section{The Present Study}

This study investigates information on victims of interpersonal violence committed by NGRI offenders during their index offence. The study uses both categorical and continuous data, and it relates victim characteristics to offender characteristics. First, information is given regarding the number of victims and the age -, gender - and relationship characteristics of every victim. It is also analyzed whether these characteristics are related to the type of the index offence. Second, several hypotheses and research questions are analyzed. Based on prior literature, we hypothesize that more adult compared to minor victims and more acquaintance compared to stranger victims will be found. We also examine whether differences can be found on gender of the victim and the nature of the acquaintance relationship. Finally, we explore whether psychotic and/or personality disordered offenders differ with respect to their victims. Since literature findings are mixed or quasi non-existent on these topics, no specific hypotheses are formulated. As such, we pose the following hypotheses and research questions:

Hypothesis 1 . There are more adult victims than minor victims per offender.

Hypothesis 2. There are more acquaintance victims than stranger victims per offender. Research Question 1. Is there a difference between the number of family victims, care victims and other victims per offender?

Research Question 2. Is there a difference between the number of female and male victims per offender? 
Research Question 3. Is there a difference regarding gender, age, and relationship of the victims after stratification for the psychiatric diagnoses of the NGRIs (psychotic vs. personality disorder vs. psychotic and personality disorder vs. other psychiatric disorder e.g., depressive disorder)?

\section{METHOD}

\section{Setting and Participants}

This multicenter study was conducted at three medium security units located in the communities of Bierbeek, Zelzate, and Rekem in Flanders (the Dutch-speaking part of Belgium). Medium security units provide a treatment setting for NGRI offenders who do not require care in a high secure hospital but are considered unsuitable for a general psychiatric ward or outpatient care. The law on NGRI offenders was recently changed (October 2016), but during the study period (2001-2010), the former internment law (Act of July 1, 1964 to Protect Society from Abnormals and Habitual Offenders) was still in effect. Article 1 and 7 of this Act lay down the conditions for internment. First, the offender must have committed a felony or misdemeanor for which the criminal law sets a minimum penalty of at least eight days. Second, the offender must be found in a state of insanity, serious mental disorder or deficiency that renders him/her unable to control his/her actions. The Court of Cassation added one further condition: the offender must be a danger to society at the moment of sentencing. The Belgian system is dichotomized between

criminally responsible and irresponsible people without further differentiation between complete irresponsibility and severely diminished responsibility. To determine responsibility, both the volitional aspect (severely or complete lack of control) and the cognitive aspect (intellectual or cognitive abilities, knowledge or insight of the criminal nature of the behavior) are considered. 
However, there is no legal standard for 'insanity' in Belgium, resulting in great discord in practice on how to interpret the law. For example, offenders suffering from paraphilia, personality disorders or substance abuse are not systematically excluded, but whether an internment measure will be imposed is largely dependent on the expert conducting the evaluation and the judges. The internment measure takes place under the supervision of a regional court, the Commission for the Protection of Society (CPS). The aim of this measure is to protect society form further offenses and provide the necessary treatment for the offender.

\section{Measures and Procedures}

A retrospective analysis was done to examine a consecutive cohort of 542 offenders admitted to one of the medium security units in Flanders during the period of 2001-2010. Ethical approval was obtained from the Medical Ethical Commission of the University Hospital of Antwerp. Informed consent was not mandatory due to the nature of the study (retrospective file study). However, one local ethical committee requested that all offenders should be informed by letter regarding the research project. Eleven offenders responded that they did not want their data being used. Therefore, these offenders were excluded from the analyses. Also, offenders with index offenses not involving victims (e.g., theft) were excluded. The remaining 373 NGRI offenders with violent index offences against people were included. The study population comprised $68.6 \%$ of the total admitted population during that period. Data from 11 patients were not analyzed because there was no information available on the victim characteristics, leaving a total study population of $N=362$.

Information on the violent index offences was retrieved from the Central Criminal Records of the Ministry of Justice and cross referenced with the different court administrations. 
Violent offences were restricted to violence toward another person, referring to the intentional use of physical force or power - threatened, attempted, or actual - against another person. For each NGRI offender, all victim characteristics were analyzed. Information on NGRI offenders was gathered through hospital files regarding demographics, type of offence, status of hospitalization, and psychiatric DSM diagnoses.

\section{Demographic characteristics of victims.}

The gender of the victim (male or female) and whether the victim was a minor or adult were recorded. The total number of victims, number of female and male victims, and the number of adult and minor victims were also noted. For every victim, the type of perpetrated violence (sexual, homicide or other violence) was analyzed.

\section{Victim-offender relationship.}

First, information was recorded about whether the victim was a stranger or an acquaintance of the offender. Stranger victims were defined as victims not known to the offender 24 hours prior to the offence, while all other victims were defined as acquaintance victims. The acquaintance victims were divided into three groups: care victims, family victims, and other victims. 'Care' victims consisted of 1) caregivers, who were broadly defined as anyone involved in the treatment or confinement of the NGRI offenders, such as nurses, doctors, or prison officers; and 2) co-residents, which referred to other psychiatric patients or other inmates. 'Family' victims consisted of 1) intimate partners defined as current or former romantic partners and 2) family victims referring to close family members such as parents and siblings. 'Other' victims comprised 1) work-related victims referring to colleagues working with the NGRI offenders at the time of the offence, 2) friends, and 3) all other victims (e.g., neighbors or children of the intimate partner). The total number of victims in each category was calculated. 
The type of violence committed against each victim was divided into homicide/attempted homicide, sexual hands-on assault, and other violent offences.

\section{Offender characteristics.}

The following demographic information was gathered with respect to the offender: age, gender, and nationality and marital status were coded. The index offence was characterized by the most serious offence. Psychiatric (primary and comorbid) diagnoses were retrieved from the evaluating clinicians and classified according to the Diagnostic and Statistical Manual of Mental Disorders, Fourth Edition, Text Revision (DSM-IV-TR; American Psychiatric Association, 2000). The first author, a psychiatrist, cross-referenced these diagnoses with relevant information (e.g., forensic psychiatric reports and psychological testing) found in the hospital and CPS files. Discrepancies were discussed with the treating psychiatrists and corrected as needed. These adjusted psychiatric diagnoses were clustered into four categories: 1) psychotic disorders without personality disorder, 2) personality disorders without psychotic disorder, 3) psychotic disorders in combination with personality disorders, and 4) patients with psychiatric diagnoses other than personality or psychotic disorders. Also, the hospitalization status of the offender was coded. We examined whether the patient was in-patient in an institution (hospital, prison) or out-patient while committing the index offence.

\section{Statistical Analyses}

SPSS Version 22 (IBM Corp, 2013) was used for the descriptive statistical analyses. Chisquare test was used to compare categorical victim characteristics between different type of index offenses. 
Repeated measures ANOVA was used for parametric data after removal of outliers in key variables based on their value of two times the standard deviation above the mean and root square transformation (Miller, 1991; Osborne, 2010). Post hoc comparisons were done using Bonferroni correction. Outliers were omitted for only the age variable. To ensure that omitting these participants would not bias the analyses, non-parametric exploratory analyses were also conducted with all participants. These analyses demonstrated similar results and are thus not reported. Repeated measures ANOVA is considered a rather robust technique, and large samples suffer less from unequal variances of the recommended skewness and kurtosis levels (Tabachnick \& Fidell, 2013). However, literature suggests that the normality distribution could be improved (Osborne, 2010). The data were considered to approach a normality distribution when the absolute skewness level was $\leq 3$ and the kurtosis level was $\leq 10$ (Kline, 2010; Tabachnick \& Fidell, 2013).

\section{RESULTS}

\section{Descriptive Statistics Offenders}

All offenders $(N=362)$ were found NGRI after having committed a violent offense. The offenders were mostly male patients ${ }^{2}$, born in Belgium, living alone at the time of the index offense. Table 1 summarizes the demographic characteristics of the study population, while Table 2 gives an overview of the psychiatric disorders. The psychiatric diagnoses were present either as a primary or as a comorbid disorder. Therefore, multiple disorders could be present per offender. Compared to other NGRI offender population, the high number of personality disorders may be noticeable. However, these disorders were comorbid disorders in the clear majority $(88 \%)$ of the cases. To conduct the analyses on the victim profiles, the psychiatric disorders of the NGRI offenders were clustered into four categories: 1) psychotic disorders without 
personality disorder $(19.6 \%, n=71), 2)$ personality disorders without psychotic disorder $(53.9 \%$, $n=195), 3)$ psychotic disorders in combination with personality disorders $(20.7 \%, n=75)$, and 4) patients with psychiatric diagnoses other than personality or psychotic disorders $(5.8 \%, n=$ 21).

- Please insert Table 1 and 2 -

On average, 2.2 victims $(S D=2.46$, range 1 - 23) were registered per offender, which led to a total of 792 identified unique victims. Regarding the victim's age, most NGRI offenders $(87.8 \%)$ exclusively victimized adult victims, whereas a few $(7.5 \%)$ had only minor victims. A minority victimized both adult and minor victims (4.7\%). Regarding the victims' gender, most NGRIs (42.9\%) exclusively victimized female victims, whereas $34.6 \%$ had only male victims, and $22.6 \%$ had both female and male victims. Regarding the victim's relationship, most NGRIs (66.4\%) exclusively victimized acquaintance victims in their index offence, whereas a minority (26.6\%) had only stranger victims, and $7.0 \%$ had both stranger and acquaintance victims.

A minority of the offenders threatened or assaulted the victims while they were inpatients $^{3}(9.4 \%, n=34)$, but the majority were out-patients $(90.6 \%, n=328)$.

\section{Descriptive Statistics Victims}

The distribution of the victim profile according to the nature of the perpetrated violence is shown in Table 3. Among the 792 identified unique victims, there was missing information regarding the victim's age $(2.6 \%, n=20)$, gender $(7.5 \%, n=58)$, and relationship to the offender 
$(6.2 \%, n=48)$. As can be seen from Table 3, there was a significant difference of the victim gender across the three categories of violence, $\chi 2(2)=10.61, p<.01$. A high number of female victims $(63.7 \%)$ was noted for the sexual offenses. There was also a significant difference with respect to victim age $(\chi 2(2)=354.67, p<.001)$, victim-offender relationship $(\chi 2(2)=14.26, p<$ $.01)$, and type of acquaintance relationship, $\chi 2(2)=96.22, p<.001$. Sexual assaults were characterized by many female $(63.7 \%)$ and minor victims $(69.8 \%)$. Many acquaintance victims $(84.5 \%)$ were found in the victims of (attempted) homicide, more specifically family members (i.e., $59.8 \%$ of the acquaintance victims). In Table 4, victim gender and age characteristics are shown for the different types of acquaintance relationships. Among the care victims, a high number of male victims $(80.3 \%)$ is found, while family victims are in majority female victims $(70.2 \%)$

- Pleases insert Table 3 and 4 -

\section{Differences According to Victim Characteristics}

For each offender, the number of victims were calculated with respect to the different victim characteristics. Regarding the victim's age, the number of adult victims per offender $(M=$ $1.22, S D=0.59)$ was significantly larger than the number of minor victims per offender $(M=$ $0.13, S D=0.37), F(1,357)=655.27, p<.001, \eta p=.65$. With respect to the victim's relationship to the offender, a significant difference was found between the number of acquaintance victims per offender $(M=0.95 S D=0.72)$ and stranger victims per offender $(M=0.42, S D=0.68), F(1$, $361)=63.57, p<.001, \eta p^{2}=.15$. Therefore, the first two hypotheses were confirmed. 
Furthermore, the results showed that there was a significant difference between the proportion of family victims $(M=0.59, S D=0.62)$, care victims $(M=0.43, S D=0.67)$, and other victims $(M$ $=0.40, S D=0.66), F(2,522)=4.99, p<.001, \eta p^{2}=.02$. Bonferroni post hoc tests were used to interpret this finding and revealed that there was a significant difference between the number of family victims compared to care and other victims, while there was no significant effect between the care and other victims.

With respect to the victim's gender, the result showed no significant difference between the number of male victims per offender $(M=0.69, S D=0.72)$ and female victims per offender $(M=0.76, S D=0.67), F(1,361)=1.85, p=.21$.

Finally, we tested whether the differences which were found would be moderated by the psychiatric diagnoses of the offenders. Regarding the victim's age, there was no interaction, $F(3$, $354)=1.94, p=.12$. No influence of psychiatric diagnoses was thus found, as more adult than minor victims occurred in all groups. With respect to the victim's gender, there was no interaction, $F(3,358)=1.34, p=.25$. No effect of psychiatric diagnoses was thus found, as no difference in gender was found in all groups. Equally, the results could not confirm the assumption that the relationship to the offender would differ when investigating several psychiatric diagnoses in the offender, $F(3,358)=1.65, p=.18$. In other words, there was no effect of psychiatric diagnoses, as more acquaintance than stranger victims occurred in all groups. Finally, no interaction effect was found with respect to the nature of the relationship, $F(6,516)=1.28, p=.27$. A significant difference between the proportion of family victims, care victims, and other victims occurred in all groups. 


\section{DISCUSSION}

This study examined the characteristics (age, gender, and relationship to the offender) of victims of different types of violence in cases of NGRI and investigated whether the psychiatric diagnoses of NGRI offenders would influence the findings. Prior scant literature already showed that MDO and NGRI offenders are more likely to be violent toward adult acquaintance victims.

So far it was still unclear how victim profiles can be characterized in relation to specific psychiatric disorders in the offenders. A first step to address this gap in the field was taken in the current study. Two important conclusions emerged. First victim profiles were not associated with psychiatric diagnoses of the offenders. Second, victims known to the offender were most frequently victimized. Our study thus further adds to the still limited evidence that stranger victimization is unlikely in cases of NGRI, as it is in MDO offenders.

Cases of NGRI in this study involved more adult victims than minor victims. This finding is in line with the observations of previous research (e.g., Gulayets, 2016) and confirms the first hypothesis. This increased number of adult victims was found for cases of NGRI in each classified disorder category. In contrast, when specifically investigating sexual assault, more than two third of the victims were minors. This finding is in line with another NGRI study that focused on sex offenders. Together, the literature highlights the need to differentiate according to the nature of the perpetrated violence (Novak et al., 2007).

As for gender, no clear pattern emerged in the present study, which is consistent with previous mixed findings on gender (Crocker et al., 2015; Gulayets, 2016). No gender differences were found for the total group, and there was no interaction effect with psychiatric diagnoses. When specifically looking at sexual assault, a third of the victims were male, which may suggest a general tendency of men to underreport such crimes. Perhaps even more so than sexual assaults 
of women, men in general have a lower likelihood of reporting victimization because of stigma, shame, or fear of having their sexuality questioned (Davies, 2002; Tewksbury, 2007). Taken together, results from prior research and the current study seem to suggest that gender is not clearly related to victimization. This observation is also in line with more broadly defined MDO populations (e.g., Liettu, Saavala, Hakko, Rasanen, \& Joukamaa, 2009; Nordstrom \& Kullgren, 2003b). However, in the general population, victims of violence tend to be more often men (Kamperman et al., 2014). Further research is needed to study separate forms of victimization such as sexual assault more in depth.

The current study further adds to the evidence that victims of violence in cases of NGRI are more often acquaintances than strangers (Crocker et al., 2015; Livingston et al., 2003). This is also consistent with results from more broadly defined MDO populations (Estroff et al., 1998; Gow et al., 2010; Gradillas et al., 2007) and confirms our second hypothesis. When investigating the type of acquaintance victim, it seemed that family members were more commonly victimized than the other groups. More specifically, in case of manslaughter/homicide, $59.8 \%$ of the acquaintance victims were family members, whereas $32.3 \%$ of the acquaintance victims were family members in the less serious violent offences. This finding is consistent with other research, which found that family victims were injured more severely than other victims (Crocker et al., 2013). According to Nordstrom and Kullgren (2003a), this finding can be explained by the higher threshold for reporting crimes within the family and stronger emotional bonds resulting in more uncontrolled violence.

A third of the acquaintance victims were caregiver victims. The risk of being assaulted or threatened by a patient is sometimes seen as a professional hazard. For example, in a forensic hospital, the one-year incidence rate of physical assault was $70 \%$, and $12 \%$ of staff were injured 
seriously enough to take time off from work (Kelly et al., 2015). In contrast, the number of copatients who were victimized (30 in total) seems to be relatively small. However, literature has revealed that the prevalence rate of victimization in psychiatric patients is much higher than in the general population, irrespective of the type of sample or type of victimization (Choe, Teplin, \& Abram, 2008; de Mooij et al., 2015; Groenhuijsen, 2015; Kamperman et al., 2014). The low number of patient victims in the present study may be due to the usage of court convictions as the data source, whereas other studies used self-reported victimization data (Choe et al., 2008; de Mooij et al., 2015). Again, no interaction effect was found for psychiatric diagnoses, which was in line with another study on MDOs (Goethals et al., 2008).

\section{Clinical Implications and Further Directions}

Although violence committed by patients with a major mental disorder is generally a low base-rate phenomenon, preventive action can be taken on several levels since the most likely victims will be acquaintances. First, the present study showed that family members were the most frequent acquaintance victims. This may not come as a surprise since it is estimated that half of the people with a serious mental illness live with their family, and three-fourths of the patients have regular contact with their family (Solomon, Cavanaugh, \& Gelles, 2005). In addition, the informal social network size of MDOs was found to be smaller than that of the general population and to consist mostly of family members (Ter Haar-Pomp, Spreen, Bogaerts, \& Volker, 2015). Thus, one explanation for the risk for family members of becoming a victim relates to the fact that they have the most contact with the MDO. Another explanation relates to the finding that there is a poor acceptance of psychiatric pathology among both patients and their family members resulting in inadequate monitoring and treatment of psychiatric patients (Marleau, Millaud, \& Auclair, 2003; Raymond, Leger, \& Lachaux, 2015). 
Lewis, Scott, Baranoski, Buchanan, and Griffith (1998) further noted that it was the erosion of the family's capacity to contain the violence that triggered a violent incident rather than a substantive change in the behavior of the patient. Setting limits on the behavior of a sick relative has been identified as another important trigger for violence (Lewis et al., 1998) and is similar to the therapeutic limit setting in institutions. It can be expected that the burden of the care of mentally ill family members will become an even greater burden as family members age, admission periods become shorter, and community-based treatment increases. Family psychoeducation and monitored aftercare should therefore be included in treatment.

Second, caregivers were the second most frequent type of acquaintance victims. Our data identified male care givers as the most frequent victims. Unfortunately, no additional information on the caregivers was available. Previous research found that direct caregivers were victimized more often than other team members (Erdos \& Hughes, 2001) and older staff were more likely to be violently victimized (Decaire, Bedard, Riendeau, \& Forrest, 2006). Furthermore, variability in the rates of reporting violence among caregivers is likely to affect the data on the number of victims. A previous study on a similar population found that violent in-patient incidents are rarely prosecuted and adjudicated (Jeandarme et al., 2017). As such, official reconviction data are a clear underestimation of the true number of caregiver victims.

It is therefore recommended that careful records of incidents and the related victims be kept to increase awareness of risk factors and situations, inform policy decisions regarding aggression management at the facility level, and eventually prevent more serious future incidents (Kobes, Nijman, \& Bulten, 2012). A clear, consistent policy regarding the prosecuting of patients is also recommended (Clark, McInerney, \& Brown, 2012; Quanbeck, 2006). To prevent violence, Cornaggia, Beghi, Pavone, and Barale (2011) stressed the need for a "good ward 
climate" with an appropriate number of nursing staff, a non-overcrowded setting, and adequate staff training (p. 18).

\section{Limitations}

Some restrictions necessitate caution when interpreting and generalizing these findings. First, information on psychiatric diagnoses was retracted from clinical records, at the discretion of the evaluating clinician. Although all relevant information was further evaluated by the researcher to improve consistency in the evaluations, this is a limitation to this study. Even though clinicians are adhering to the DSM, there may be some variability in how they derive diagnoses due to not using a standardized tool (like the MINI). Also, it may be interesting to compare other clusters of psychiatric diagnoses in future research, e.g., not lumping all personality disordered patients together. Second, our results may not generalize to other countries with different legal systems and statutes. Third, when using official files to determine crime rates, the problem of hidden victimization or dark numbers needs to be considered. Dark numbers refer to the offences that are not officially registered. Namely, many offences are not reported to the police, and the reported offences do not always result in charges, let alone convictions. As a result, conviction rates underestimate offenses. This issue might be particularly relevant for family and caregiver victims, who may feel reluctant to file a formal complaint. Despite these concerns, we chose to use official offense data since they are considered as a reliable measure of crime and recidivism (Wartna, 2009).

Finally, no comparison group of criminally responsible offenders was used. In a small study, Nestor and Haycock (1997) found that NGRI murderers were more likely to kill blood relatives, especially parents, whereas convicted murderers were more likely to kill a significant other, such as a lover or a spouse. Homicide victims of MDOs were less likely to be strangers 
and more likely to be a family member or partner compared to homicide victims of not mentally disordered offenders (Shaw et al., 1999). Remarkably, Steadman et al. (1998) found that the targets of violence in a patient group were similar to those of a comparison group of people living in the same neighborhood. Based on these mixed findings, further research with comparison groups is needed.

\section{Conclusion}

Knowledge on victim characteristics of NGRI offenders may enhance treatment of offenders and the prevention of future victims. The current study demonstrated that these victims are often adults who are known to the offender and in general equally likely to be male or female. Compared to MDO offenders, minimal differences were found in our NGRI population. Further analyses suggested that these profile characteristics of victims are highly similar for perpetrators with different psychiatric diagnoses. Differences did exist when looking at the different types of perpetrated violence. For example, a gender and age difference emerged when studying sexual assault. Gender differences were noted among the acquaintance victims with a high number of female family victims and male care victims. Together, our results on the gender, age, and relationship of the victim may inform and help practitioners to recognize potential risk situations. 


\section{References}

Bader, S., Evans, S. E., \& Welsh, E. (2014). Aggression Among Psychiatric Inpatients: The Relationship Between Time, Place, Victims, and Severity Ratings. Journal of the American Psychiatric Nurses Association, 20(3), 179-186. doi:10.1177/1078390314537377

Bowers, L., Stewart, D., Papadopoulos, C., Dack, C., Ross, J., Khanom, H., \& Jeffery, D. (2011). Inpatient violence and aggression: A literature review. London: Kings College.

Choe, J. Y., Teplin, L. A., \& Abram, K. M. (2008). Perpetration of violence, violent victimization, and severe mental illness: balancing public health concerns. Psychiatric Services, 59(2), 153-164. doi:10.1176/appi.ps.59.2.153

Cirincione, C., Steadman, H. J., \& McGreevy, M. A. (1995). Rates of insanity acquittals and the factors associated with successful insanity pleas. The Bulletin of the American Academy of Psychiatry and the Law, 23(3), 399-409.

Clark, C. R., McInerney, B. A., \& Brown, I. (2012). The prosecution of psychiatric inpatients: Overcoming the barriers. The Journal of Forensic Psychiatry \& Psychology, 23(3), 371381. doi:10.1080/14789949.2012.686622

Coid, J., Kahtan, N., Gault, S., Cook, A., \& Jarman, B. (2001). Medium secure forensic psychiatry services: comparison of seven English health regions. The British Journal of Psychiatry, 178(1), 55-61.

Cornaggia, C. M., Beghi, M., Pavone, F., \& Barale, F. (2011). Aggression in psychiatry wards: A systematic review. Psychiatry Research, 189(1), 10-20. doi:10.1016/j.psychres.2010.12.024

Crocker, A. G., Nicholls, T. L., Seto, M. C., Charette, Y., Cote, G., \& Caulet, M. (2015). The national trajectory project of individuals found not criminally responsible on account of mental disorder in Canada. Part 2: the people behind the label. The Canadian Journal of Psychiatry, 60(3), 106-116.

Crocker, A. G., Seto, M. C., Nicholls, T. L., \& Côté, G. (2013). Description and processing of inidviduals found Not Criminally Responsible on Account of Metnal Disorder accused of "serious violent offences". Canada.

Daffern, M., Mayer, M., \& Martin, T. (2003). A preliminary investigation into patterns of aggression in an Australian forensic psychiatric hospital. The Journal of Forensic Psychiatry \& Psychology, 14(1), 67-84.

Davies, M. (2002). Male sexual assault victims: a selective review of the literature and implications for support services. Aggression and Violent Behavior, 7, 203-214.

de Mooij, L. D., Kikkert, M., Lommerse, N. M., Peen, J., Meijwaard, S. C., Theunissen, J., . . . Dekker, J. J. (2015). Victimisation in adults with severe mental illness: prevalence and risk factors. The British Journal of Psychiatry, 207(6), 515-522.

doi:10.1192/bjp.bp.113.143370 
Decaire, M. W., Bedard, M., Riendeau, J., \& Forrest, R. (2006). Incidents in a psychiatric forensic setting: association with patient and staff characteristics. The Canadian Journal of Nursing Research, 38(3), 68-80.

Erdos, B. Z., \& Hughes, D. H. (2001). Emergency psychiatry: a review of assaults by patients against staff at psychiatric emergency centers. Psychiatric Services, 52(9), 1175-1177. doi:10.1176/appi.ps.52.9.1175

Estroff, S. E., Swanson, J. W., Lachicotte, W. S., Swartz, M., \& Bolduc, M. (1998). Risk reconsidered: targets of violence in the social networks of people with serious psychiatric disorders. Social Psychiatry and Psychiatric Epidemiology, 33 Suppl 1, S95-101.

Goethals, K., Gaertner, W., Buitelaar, J., \& van Marle, H. (2008). Targets of violence and psychosocial problems in psychotic offenders detained under the Dutch Entrustment Act. The Journal of Forensic Psychiatry \& Psychology, 19(4), 561-575.

Gow, R., Choo, M., Darjee, R., Gould, S., \& Steele, J. (2010). Research articles A demographic study of the Orchard Clinic: Scotland's first medium secure unit. The Journal of Forensic Psychiatry \& Psychology, 21(1), 139-155.

Gradillas, V., Williams, A., Walsch, E., \& Fahy, T. (2007). Do forensic psychiatric inpatient units pose a risk to local communities. The Journal of Forensic Psychiatry \& Psychology, 18(2), 261-265. doi:10.1080/14789940701246360

Groenhuijsen, M. (2015). Victimological aspects of reporting and not reporting crimes: A general overview. In T. Tollefson (Ed.), Victimological advances in theory, policies and services. A general overview (pp. 111-120). Fresno: Dummond Printing.

Gulayets, M. (2016). Exploring Differences between Successful and Unsuccessful Mental Disorder Defences. Canadian Journal of Criminology and Criminal Justice, 58(2), 1-33. doi:http://dx.doi.org/10.3138/cjccj.2014.E14

IBM Corp. (2013). IBM SPSS statistics for windows, version 22.0. Armonk, NY: IBM Corp.

Jeandarme, I., Wittouck, C., Vander Laenen, F., Pouls, C., Heimans, H., Oei, T. I., \& Bogaerts, S. (2017). Critical incidents and judicial response during medium security treatment. Int J Law Psychiatry, 51, 54-61. doi:10.1016/j.ijlp.2016.12.001

Johnston, I., \& Taylor, P. J. (2003). Mental disorder and serious violence: the victims. The Journal of Clinical Psychiatry, 64(7), 819-824.

Kamperman, A. M., Henrichs, J., Bogaerts, S., Lesaffre, E. M., Wierdsma, A. I., Ghauharali, R. R., . . Mulder, C. L. (2014). Criminal victimisation in people with severe mental illness: a multi-site prevalence and incidence survey in the Netherlands. PLoS One, 9(3), e91029. doi:10.1371/journal.pone.0091029

Kelly, E. L., Subica, A. M., Fulginiti, A., Brekke, J. S., \& Novaco, R. W. (2015). A crosssectional survey of factors related to inpatient assault of staff in a forensic psychiatric hospital. Journal of Advanced Nursing, 71(5), 1110-1122. doi:10.1111/jan.12609

Kline, R. (2010). Principles and practices of structural equation modeling (3rd Ed.). New York, NY: Guilford Press.

Kobes, M. H., Nijman, H. H., \& Bulten, E. B. (2012). Assessing aggressive behavior in forensic psychiatric patients: validity and clinical utility of combining two instruments. Archives of Psychiatric Nursing, 26(6), 487-494. doi:10.1016/j.apnu.2012.04.004

Lewis, M. E., Scott, D. C., Baranoski, M. V., Buchanan, J. A., \& Griffith, E. E. (1998). Prototypes of intrafamily homicide and serious assault among insanity acquittees. The Journal of the American Academy of Psychiatry and the Law, 26(1), 37-48. 
Liettu, A., Saavala, H., Hakko, H., Rasanen, P., \& Joukamaa, M. (2009). Mental disorders of male parricidal offenders: a study of offenders in forensic psychiatric examination in Finland during 1973-2004. Social Psychiatry and Psychiatric Epidemiology, 44(2), 96103. doi:10.1007/s00127-008-0419-9

Livingston, J. D., Wilson, D., Tien, G., \& Bond, L. (2003). A follow-up study of persons found not criminally responsible on account of mental disorder in British Columbia. The Canadian Journal of Psychiatry, 48(6), 408-415.

Maniglio, R. (2009). Severe mental illness and criminal victimization: a systematic review. Acta Psychiatrica Scandinavica, 119(3), 180-191. doi:10.1111/j.1600-0447.2008.01300.x

Marleau, J. D., Millaud, F., \& Auclair, N. (2003). A comparison of parricide and attempted parricide: a study of 39 psychotic adults. International Journal of Law and Psychiatry, 26(3), 269-279. doi:10.1016/S0160-2527(03)00037-2

Menezes , S., Oyebode, F., \& Haque, M. (2009). Victims of mentally disordered offenders in Zimbabwe, 1980-1990. The Journal of Forensic Psychiatry \& Psychology, 20(3), 427439.

Mezey, G. (2007). Victims and forensic psychiatry: marginal or mainstream. Criminal Behaviour and Mental Health, 17(3), 131-136. doi:10.1002/cbm.655

Miller, J. (1991). Reaction time analysis with outlier exclusion: Bias varies with sample size. The Quarterly Journal of Experimental Psychology, 43(4), 907-912.

Nestor, P. G., \& Haycock, J. (1997). Not guilty by reason of insanity of murder: clinical and neuropsychological characteristics. The Journal of the American Academy of Psychiatry and the Law, 25(2), 161-171.

Nicholls, T. L., Brink, J., Greaves, C., Lussier, P., \& Verdun-Jones, S. (2009). Forensic psychiatric inpatients and aggression: an exploration of incidence, prevalence, severity, and interventions by gender. International Journal of Law and Psychiatry, 32(1), 23-30. doi:10.1016/j.ijlp.2008.11.007

Nordstrom, A., \& Kullgren, G. (2003a). Do violent offenders with schizophrenia who attack family members differ from those with other victims? International Journal of Forensic Mental Health, 2(2), 195-200.

Nordstrom, A., \& Kullgren, G. (2003b). Victim relations and victim gender in violent crimes committed by offenders with schizophrenia. Social Psychiatry and Psychiatric Epidemiology, 38(6), 326-330. doi:10.1007/s00127-003-0640-5

Novak, B., McDermott, B. E., Scott, C. L., \& Guillory, S. (2007). Sex offenders and insanity: an examination of 42 individuals found not guilty by reason of insanity. The Journal of the American Academy of Psychiatry and the Law, 35(4), 444-450.

Osborne, J. (2010). Improving your data transformations: Applying the Box-Cox transformation. Practical Assessment, Research \& Evaluation, 15(12), 1-9.

Parker, G. (2004). Outcomes of assertive community treatment in an NGRI conditional release program. J Am Acad Psychiatry Law, 32(3), 291-303.

Parker, I. (1987). Homicide and the Insanity Defense: A Comparison of Sane and Insane Murderers. Behavioral Sciences \& the Law, 5(1), 25-35.

Pinna, F., Tusconi, M., Dessi, C., Pittaluga, G., Fiorillo, A., \& Carpiniello, B. (2016). Violence and mental disorders. A retrospective study of people in charge of a community mental health center. Int J Law Psychiatry, 47, 122-128. doi:10.1016/j.ijlp.2016.02.015 
Quanbeck, C. (2006). Forensic psychiatric aspects of inpatient violence. The Psychiatric Clinics of North America, 29(3), 743-760. doi:10.1016/j.psc.2006.04.011

Raymond, S., Leger, A. S., \& Lachaux, B. (2015). A descriptive and follow-up study of 40 parricidal patients hospitalized in a French secure unit over a 15-year period.

International Journal of Law and Psychiatry, 41, 43-49. doi:10.1016/j.ijlp.2015.03.006

Shaw, J., Appleby, L., Amos, T., McDonnell, R., Harris, C., McCann, K., . . Parsons, R. (1999). Mental disorder and clinical care in people convicted of homicide: national clinical survey. British Medical Journal, 318(7193), 1240-1244.

Solomon, P. L., Cavanaugh, M. M., \& Gelles, R. J. (2005). Family violence among adults with severe mental illness: a neglected area of research. Trauma, Violence \& Abuse, 6(1), 4054. doi:10.1177/1524838004272464

Steadman, H. J., Mulvey, E. P., Monahan, J., Robbins, P. C., Appelbaum, P. S., Grisso, T., .. . Silver, E. (1998). Violence by people discharged from acute psychiatric inpatient facilities and by others in the same neighborhoods. Archives of General Psychiatry, 55(5), 393-401.

Swanson, J., Swartz, M., Estroff, S., Borum, R., Wagner, R., \& Hiday, V. (1998). Psychiatric impairment, social contact, and violent behavior: evidence from a study of outpatientcommitted persons with severe mental disorder. Social Psychiatry and Psychiatric Epidemiology, 33 Suppl 1, S86-94.

Tabachnick, B. G., \& Fidell, L. S. (2013). Using Multivariate Statistics (6th Ed.). New Jersey, NJ: Pearson Education Inc.

Tardiff, K., Marzuk, P. M., Leon, A. C., \& Portera, L. (1997). A prospective study of violence by psychiatric patients after hospital discharge. Psychiatric Services, 48(5), 678-681. doi:10.1176/ps.48.5.678

Ter Haar-Pomp, L., Spreen, M., Bogaerts, S., \& Volker, B. (2015). The personal social networks of personality disordered forensic psychiatric patients. Journal of Social Work, 15(3), 254-276.

Tewksbury, R. (2007). Effects of Sexual Assaults on Men: Physical, Mental and Sexual Consequences. International Journal of Men's Health, 6(1), 22-35.

Wartna, B. S. J. (2009). In de oude fout. Over het meten van recidive en het vaststellen van het succes van strafrechtelijke interventies. Den Haag: WODC.

Weizmann-henelius, G., \& Suutala, H. (2000). Violence in a Finnish forensic psychiatric hospital. Nordic Journal of Psychiatry, 54, 269-273. 


\section{Footnotes}

${ }^{1}$ In Canada, NGRI offenders are referred to as offenders Not Criminally Responsible on Account of Mental Disorder (NCRMD). The term NGRI is used throughout the manuscript referring to similar populations in different countries.

${ }^{2}$ A minority of the NGRI offenders were females $(5.5 \%, n=20)$. Due to this small sample size, data were not analysed for female offenders separately. In addition, excluding the females did not change the results.

${ }^{3}$ Either during psychiatric admission $(n=27)$, during detention $(n=5)$ or while residing in a shelter $(\mathrm{n}=2)$. 